\title{
Diversity and flexibility of Th17 effector functions
}

Thomas Kamradt* ${ }^{*}$ and Hyun-Dong Chang ${ }^{2}$

\begin{abstract}
IL-17-producing CD4+ T-helper cells (Th17 cells) have been recognised as important drivers of pathogenesis in a multitude of inflammatory diseases, including arthritis. The cytokines and transcription factors that instruct and execute Th17 lineage differentiation have been identified. This has induced hopes that targeting Th17 cells might yield a magic bullet against autoimmune diseases. A new wave of published reports shows that matters are more complicated: Th cells can coexpress IL-17 with a variety of other cytokines, including IFNY, IL-4, or IL-10, with different functional consequences. Moreover, IL-17 memory is not stable - Th17 cells can be instructed to express other lineage-defining cytokines and to halt IL-17 expression. Finally, Th17 cells may exert tissueprotective effects, even in the context of some inflammatory diseases. Manipulating Th17 cells or IL-17 effects may be more difficult than initially appreciated. Notwithstanding these facts, IL-17 remains a valuable and even more interesting therapeutic target.
\end{abstract}

Cytokines produced by CD4+ $\mathrm{T}$-helper (Th) lymphocytes are critical for protective and pathogenic immune responses. According to their cytokine production, Th cells can be categorised into at least four functionally distinct lineages, called Th1, Th2, Th17, and Treg. Differentiation of naive Th cells is induced upon antigen recognition in the presence of instructive cytokines, resulting in the upregulation of so-called master transcription factors - that is, T-bet, GATA-3, retinoic acid-related orphan receptor $\gamma \mathrm{t}$ (ROR $\gamma \mathrm{t}$ ), or FoxP3 for Th1, Th2, Th17, or Treg cells, respectively - and imprinting of functionally relevant genes, such as genes encoding for cytokines and chemokine receptors [1,2].

\footnotetext{
*Correspondence: immunologie@mti.uni-jena.de

'Institut für Immunologie, Universitätsklinikum Jena, Leutragraben 3, 07740 Jena, Germany

Full list of author information is available at the end of the article
}

Th17 cells were originally characterised by their coexpression of IL-17 (also called IL-17A) together with IL-17F, TNF $\alpha$, granulocyte-macrophage colony-stimulating factor, and lymphotactin, but not Th1 or Th2 cytokines [3,4]. Over the past several years it has become clear that Th17 cells do not represent a homogeneous lineage. IL-17 can be coexpressed with a variety of other cytokines including IL-21, IL-22, IFN $\gamma$, IL-10, and IL-4, with consequences for the cells' functionality [1,2,5-7]. Moreover, IL-17 is not exclusively produced by $\mathrm{CD} 44^{+}$ cells but also by $\mathrm{CD}^{+} \mathrm{T}$ cells, $\gamma \delta \mathrm{T}$ cells, natural killer $\mathrm{T}$ cells, natural killer cells, and perhaps also neutrophils, mast cells, and others [2]. Not all IL-17 producers therefore are Th17 cells. One possible current definition of Th17 cells would be CD4+ Th cells that express IL-17A, the IL-23 receptor, and CCR6, and have high levels of expression of the transcription factor RORyt in the absence of significant expression of other lineage-specific transcription factors and cytokines. In humans, CD161 expression has been described as a surface marker for Th17 cells [7].

IL-17A and IL-17F are highly homologous (50\% amino acid identity) and share the same receptor. Yet they perform distinct functions. IL-17A seems to be more relevant for the development of autoimmunity and inflammation than IL-17F, and also plays important roles in the host defence against bacterial and fungal infections, whereas IL-17F is mainly involved in mucosal host defence mechanisms [8].

The main physiological function of IL-17 is the recruitment, activation, and migration of neutrophils. Consequently, IL-17 is critically involved in defence against extracellular pathogens, including fungi [9]. Lack of Th17 differentiation or function results in increased susceptibility to extracellular bacterial and fungal infections in humans $[10,11]$.

Th17 cells are central for the pathogenesis in many murine models of inflammatory diseases. These cells contribute to inflammation through the recruitment of neutrophils and the induction of secretion of proinflammatory mediators such as IL-6, IL-8, TNF $\alpha$, IL-1 $\beta$, CXCL1, CXCL10, and matrix metalloproteinases from tissue cells $[4,9]$. In particular, IL-17 is pathogenetically relevant in most murine models of arthritis with the notable exception of proteoglycan-induced arthritis, 
which is IFN $\gamma$ dependent $[4,12]$. Injection of IL-17 into a mouse knee joint induces cartilage degradation, and IL-17 overexpression induces bone erosion and cartilage degradation [12]. In man, acting synergistically with IL-1 and TNF $\alpha$, IL-17 was originally shown to induce massive IL-6 production in synovial fibroblasts [4]. The frequency of IL-17-producing cells in the synovium correlates with disease severity in juvenile idiopathic arthritis, rheumatoid arthritis, and psoriatic arthritis [13,14]. In addition, there is a wealth of data demonstrating the presence of IL-17 in inflammatory lesions in other diseases.

While the prevailing view holds Th17 cells responsible for pathology in most inflammatory diseases, recent data also support a tissue-protective function of IL-17 in models of graft versus host disease, colitis, and bronchial hyperreactivity [2]. Whether IL-17-producing Th cells exert pathogenic or protective effects depends partly on coexpressed cytokines, tissue-specific factors, and the pathogenesis stage. Th cells that coexpress IL-17 and IL-22 together with Th2 cytokines contribute to the pathogenesis of human asthma and a murine model thereof [6], whereas IL-17 alone suppresses bronchial hypersensitivity in the effector phase of the disease.

In a murine model for multiple sclerosis (experimental autoimmune encephalitis), Th cells that recognise a myelin autoantigen and produce IL-17, IL-22, CXCL10, CCL2, and CCL5 induce disease upon adoptive transfer into recipients. In contrast, IL-17-producing Th cells recognising the same myelin autoantigen, which produce IL-17 together with IL-10, IL-22, and CCL20, are unable to cause disease and even protect recipient mice from the pathogenic effect of the aforementioned IL-17 producers [5]. In humans, IL-17-producing ROR $\gamma \mathrm{t}^{+}$Foxp $3^{+} \mathrm{T}$ cells that retain their ability to suppress effector lymphocytes have been described $[9,15]$. It is noteworthy in this context that transforming growth factor beta is an important instructive signal for the development of both Th17 and iTregs. In response to IL-6, the transcription factor IRF-4 suppresses FoxP3 expression while increasing RORyt expression, resulting in the development of Th17 cells rather than iTregs [16].

Th17 cells can be converted into other Th subtypes or nonclassical Th17 cells that coexpress other lineagedefining cytokines $[1,2,7,9,15,17]$. It has become obvious that the expression of cytokines and master transcription factors is flexible in Th cells $[1,2,9,15,17]$, breaking the dogma of fixed Th lineages. A thorough appreciation of the flexibility inherent in Th-cell cytokine production will probably halt the currently popular tendency to label every Th cell that produces a particular combination of cytokines as a distinct T-cell lineage. For example, Th17 cells can be converted into Th1/Th17 cells expressing both IFN $\gamma$ and IL-17 by combined IFN $\gamma$ and IL-12 signalling. IFN $\gamma$ is required to upregulate expression of the IL-12R $\beta 2$ chain, and IL-12 is required for Th1 polarisation. These Th1/Th17 cells stably coexpress RORyt and T-bet [17]. Such flexibility is pathogenetically relevant. Diabetes induction by adoptive transfer of highly purified Th17 cells expressing the diabetogenic BDC2.5 T-cell receptor could surprisingly be prevented with antibodies against IFNy but not with anti-IL-17 antibodies. Isolation and re-analysis of the transferred Th17 cells showed that they had downregulated ROR $\gamma \mathrm{t}$ and IL-17 expression and had upregulated T-bet and IFNy [18]. Jenkins and coworkers demonstrated that Th17 cells elicited in response to Listeria monocytogenes declined faster after the infection than did Th1 cells [19]. Their results suggest that Th17 cells are less likely to give rise to long-lived memory Th cells, although it is not clear whether the Th17 cells have lost their IL-17 expression or have died.

In conclusion, given the highly complex mechanisms of differentiation, cytokine coexpression, and pathogenic or protective effector functions of Th17 cells, the specific modulation of Th17 effector functions is a major therapeutic challenge. Current treatment options for autoimmune diseases include the blockade of IL-1, IL-6, and IL-23 (p40). Since these cytokines are relevant for the induction or maintenance of Th17 cells, the therapeutic efficacy may partly be due to reduced IL-17 production. Two humanised antibodies against IL-17A are currently in clinical trial for rheumatoid arthritis, psoriasis, and uveitis, and the first results look promising [20,21]. The effects of blocking IL-17F alone or together with IL-17A or other IL-17 family members in patients are not yet known. One can safely assume that much will be learned about the relevance of IL-17 family members for human diseases once the data from large clinical trials are publicly available.

\section{Abbreviations}

CCL, CC chemokine ligand; CXCL, CXC chemokine ligand; FoxP3, Forkhead box protein 3; IFN, interferon; IL, interleukin; iTreg, inducible regulatory $T$ cell; RORyt, retinoic acid-related orphan receptor $y t$; Th, T helper; TNF, tumour necrosis factor; Treg, regulatory $T$ cell.

\section{Author details}

${ }^{1}$ Institut für Immunologie, Universitätsklinikum Jena, Leutragraben 3, 07740 Jena, Germany. ${ }^{2}$ Deutsches Rheumaforschungszentrum Berlin, 10115 Berlin Germany.

\section{Competing interests}

The authors declare that they have no competing interests.

\section{Published: 18 April 2011}

\section{References}

1. Zhu J, Yamane H, Paul WE: Differentiation of effector CD4 T cell populations. Annu Rev Immunol 2010, 28:445-489.

2. O'Connor W, Jr, Zenewicz LA, Flavell RA: The dual nature of $\mathrm{T}(\mathrm{H}) 17$ cells: shifting the focus to function. Nat Immuno/ 2010, 11:471-476.

3. Infante-Duarte C, Horton HF, Byrne MC, Kamradt T: Microbial lipopeptides induce the production of IL-17 in Thelper (Th) cells. J Immuno/ 2000, 
165:6107-6115

4. van den Berg WB, Miossec P: IL-17 as a future therapeutic target for rheumatoid arthritis. Nat Rev Rheumatol 2009, 5:549-553.

5. McGeachy MJ, Bak-Jensen KS, Chen Y, Tato CM, Blumenschein W, McClanahan T, Cua DJ: TGF- $\beta$ and IL- 6 drive the production of IL- 17 and IL-10 by T cells and restrain T(H)-17 cell-mediated pathology. Nat Immunol 2007, 8:1390-1397.

6. Wang YH, Voo KS, Liu B, Chen CY, Uygungil B, Spoede W, Bernstein JA, Huston DP, Liu YJ: A novel subset of CD4(+) T(H)2 memory/effector cells that produce inflammatory IL-17 cytokine and promote the exacerbation of chronic allergic asthma. J Exp Med 2010, 207:2479-2491.

7. Annunziato F, Romagnani S: Do studies in humans better depict Th17 cells? Blood 2009, 114:2213-2219.

8. Iwakura Y, Ishigame H, Saijo S, Nakae S: Functional specialization of interleukin-17 family members. Immunity 2011, 34:149-162.

9. Littman DR, Rudensky AY: Th17 and regulatory T cells in mediating and restraining inflammation. Cell 2010, 140:845-858.

10. de Beaucoudrey L, Puel A, Filipe-Santos O, Cobat A, Ghandil P, Chrabieh M, Feinberg J, von Bernuth H, Samarina A, Jannière L, Fieschi C, Stéphan JL, Boileau C, Lyonnet S, Jondeau G, Cormier-Daire V, Le Merrer M, Hoarau C, Lebranchu Y, Lortholary O, Chandesris MO, Tron F, Gambineri E, Bianchi L, Rodriquez-Gallego C, Zitnik SE, Vasconcelos J, Guedes M, Vitor AB, Marodi L, et al: Mutations in STAT3 and IL12RB1 impair the development of human IL-17-producing T cells. J Exp Med 2008, 205:1543-1550.

11. Puel A, Cypowyj S, Bustamante J, Wright JF, Liu L, Lim HK, Migaud M, Israel L, Chrabieh M, Audry M, Gumbleton M, Toulon A, Bodemer C, El-Baghdadi J, Whitters M, Paradis T, Brooks J, Collins M, Wolfman NM, Al-Muhsen S, Galicchio M, Abel L, Picard C, Casanova JL: Chronic mucocutaneous candidiasis in humans with inborn errors of interleukin-17 immunity. Science 2011, 332:65-68.

12. Lubberts E:Th17 cytokines and arthritis. Semin Immunopatho/ 2010 32:43-53.

13. Nistala K, Adams S, Cambrook H, Ursu S, Olivito B, de Jager W, Evans JG, Cimaz R, Bajaj-Elliott M, Wedderburn LR: Th17 plasticity in human autoimmune arthritis is driven by the inflammatory environment. Proc Natl Acad Sci U S A 2010, 107:14751-14756.
14. Leipe J, Grunke M, Dechant C, Reindl C, Kerzendorf U, Schulze-Koops H, Skapenko A: Role of Th17 cells in human autoimmune arthritis. Arthritis Rheum 2010, 62:2876-2885.

15. Beriou G, Costantino CM, Ashley CW, Yang L, Kuchroo VK, Baecher-Allan C, Hafler DA: IL-17-producing human peripheral regulatory T cells retain suppressive function. Blood 2009, 113:4240-4249.

16. Brüstle A, Heink S, Huber M, Rosenplänter C, Stadelmann C, Yu P, Arpaia E, MakT, Kamradt T, Lohoff M: The development of inflammatory $\mathrm{T}(\mathrm{H})-17$ cells requires interferon-regulatory factor 4. Nat Immunol 2007, 8:958-966.

17. Lexberg MH, Taubner A, Albrecht I, Lepenies I, Richter A, Kamradt T, Radbruch A, Chang H-D: IFN- $\gamma$ and IL-12 synergize to convert in vivo-generated Th17 into Th1/17 cells. Eur J Immunol 2010, 40:3017-3027.

18. Bending D, De La Pena H, Veldhoen M, Phillips JM, Uyttenhove C, Stockinger B, Cooke A: Highly purified Th17 cells from BDC2.5NOD mice convert into Th1-like cells in NOD/SCID recipient mice. J Clin Invest 2009, 119:565-572.

19. Pepper M, Linehan JL, Pagan AJ, Zell T, Dileepan T, Cleary PP, Jenkins MK: Different routes of bacterial infection induce long-lived TH1 memory cells and short-lived TH17 cells. Nat Immunol 2009, 11:83-89.

20. Genovese MC, Van den Bosch F, Roberson SA, Bojin S, Biagini IM, Ryan P, Sloan-Lancaster J: LY2439821, a humanized anti-interleukin-17 monoclonal antibody, in the treatment of patients with rheumatoid arthritis: a phase I randomized, double-blind, placebo-controlled, proof-of-concept study. Arthritis Rheum 2010, 62:929-939.

21. Hueber W, Patel DD, Dryja T, Wright AM, Koroleva I, Bruin G, Antoni C, Draelos Z, Gold MH; Psoriasis Study Group, Durez P, Tak PP, Gomez-Reino JJ; Rheumatoid Arthritis Study Group, Foster CS, Kim RY, Samson CM, Falk NS, Chu DS, Callanan D, Nguyen QD; Uveitis Study Group, Rose K, Haider A, Di Padova F: Effects of AIN457, a fully human antibody to interleukin-17A, on psoriasis, rheumatoid arthritis, and uveitis. Sci Trans/Med 2010, 2:52ra72.

doi:10.1186/ar3296

Cite this article as: Kamradt T, Chang HD: Diversity and flexibility of Th17 effector functions. Arthritis Research \& Therapy 2011, 13:106. 